\title{
COMBINED PENETROMETER AND STANDING WAVE RATIO PROBE TO MEASURE COMPACTNESS AND MOISTURE CONTENT OF SOILS
}

\author{
TIAN, H. ${ }^{1,3,4}-$ GAO, C. ${ }^{2}-$ ZHAO, Y..$^{1,3,4^{*}}$ \\ ${ }^{I}$ School of Technology, Beijing Forestry University, Beijing 100083, China \\ ${ }^{2}$ School of Computer and Information Engineering, Beijing Technology and Business \\ University, Beijing 100048, China \\ ${ }^{3}$ Beijing Laboratory of Urban and Rural Ecological Environment, Beijing Municipal Education \\ Commission, Beijing 100083, China \\ ${ }^{4}$ Key Lab of State Forestry Administration for Forestry Equipment and Automation, Beijing \\ 100083, China \\ *Corresponding author \\ e-mail: yandongzh@bjfu.edu.cn; phone: +86-158-1021-0957 \\ (Received 23 ${ }^{\text {rd }}$ May 2019; accepted 28 $8^{\text {th }}$ Aug 2019)
}

\begin{abstract}
Compactness and moisture content are important and mutually influential soil parameters that affect plant growth, nutrient absorption, and nutrient transportation. To simultaneously measure these two parameters, we developed a combined penetrometer standing wave ratio (PSWR) probe; acceleration measurement was facilitated to eliminate the error caused by varying penetration speeds. The performance of the instrument was analyzed and verified through laboratory and field measurements. The cone-index measurements from an SC-900 sensor and the moisture content calculated by the drying method and a TDR sensor were used to evaluate the performance. The results prove that acceleration compensations can improve the accuracy of cone-index measurements. Further, the sensitive range of the PSWR probe was the area a $10 \mathrm{~cm}$ diameter. The linear-fitting coefficient of output voltage and volumetric moisture content exceeded 0.96, and the output was stable; therefore, the moisture content measurements using the PSWR probe were validated. Furthermore, the accuracy and stability of measurements using the PSWR probe and a TDR sensor were similar. The field-measurement results agreed with the results from the drying method, and satisfied the practical implementation requirements. Conclusively, the validated efficiency and the cost-effective stainless-steel structure of the probe render it suitable for practical applications.
\end{abstract}

Keywords: cone index, soil volumetric moisture content, penetrating acceleration, measuring radius, performance analysis

\section{Introduction}

Soil is a loose, porous, dielectric material composed of water, air, and soil particles (Schaap, et al., 1997). The compactness and moisture content are important soil parameters that affect the plant growth, water movement, seedling emergence, and root penetration (Cui et al., 2015; Goutal et al., 2013; Ogée and Brunet, 2002). In early days, soil compactness was measured primarily by destructive sampling (Ronai and Shmulevich, 1995); later, instruments based on pressure-based soil cone-index measurement (ASABE Standards, 2009; Erbach et al., 1991; Pillinger et al., 2018; Perumpral, 1987), microwave reflection measurement (Luo and Perumpral, 1995; Zoughi et al.,1994), and volume and porosity measurement were used (Ronai and Shmulevich, 1995). In the recent years, CT technology has been used to scan the soil to 
analyze its compactness (Mossadeghi-Björklund et al., 2016). The measurement techniques for soil moisture are primarily classified into sampling and in-situ techniques. Drying method is typically used to analyze the moisture content in the sampling techniques, and electrical measurements are conducted in localization techniques. In 1980, Topp et al. proposed the use of time-domain reflectometry in the field of soil moisture measurement (Topp et al., 1980). The Topp equation brought a new dimension to the soil moisture evaluation. In addition, many scholars have developed moisture measurement devices using electrical measurement methods (JinHong et al., 2008; Tranter et al., 2008; Zegelin et al., 1989).

Topp et al. initiated the research on the simultaneous measurement of compactness and moisture of the soil. For this purpose, they attempted to combine a cone penetrometer with a TDR moisture sensor. They installed a waveguide coil and mounted it on a static cone for simultaneous measurement (Topp, 2003; Yanuka et al., 1988). Vaz et al. installed the waveguide coil on the conical head of a dynamic cone (Vaz et al., 2001; Vaz and Hopmans, 2001). However, this device takes 10 min to complete a measurement, and its practical application is difficult; therefore, it is still in the laboratory research stage. Subsequently, Hummel proposed a composite sensor combining the cone-index and near-infrared methods (Hummel et al., 2004). Although this sensor could quickly synchronize the measurement, it had a complicated structure and was expensive. In 1997, Singh et al. proposed to embed an FD-type soil-moisture sensor on the head of the cone to ensure that the measurement structure of the cone is not damaged (Singh et al., 1997). Sun et al. further embedded FD-type moisture sensors into cones in 2003 and developed composite sensors in 2004 (Sun et al., 2004). Lin et al. designed a composite cone-index and moisture measurement device in 2014 (Lin et al., 2014). In order to avoid the influence of uneven insertion speed on the measurement results of compactness, ASABE stipulates that penetration speed should be uniform with a maximum penetration speed of $30 \mathrm{~mm} \cdot \mathrm{s}^{-1}$ (ASABE Standards, 2009).

The concept of combined measurement of compactness and moisture content was previously presented and designed, but there are two disadvantages in the existing systems. First, during the practical application, the operator faces difficulties in maintaining a uniform speed of penetration, which leads to errors in the cone-index measurement; second, such instruments are very expensive. Therefore, this study aimed to design and evaluate a low-cost standing wave ratio probe to be used in combination with a cone penetrometer to determine the moisture content and compactness of the soil, and to reduce the error caused by the non-uniform penetration speed by facilitating acceleration measurement. The combined PSWR probe was first tested in the laboratory, and the results were analyzed. Further, field measurements were conducted, and the results are presented.

\section{Materials and methods}

\section{PSWR probe design}

As shown in Figure la, the structure of the penetrometer consists of a cone head, a connecting rod, and a fixed base. The cone head and the connecting rod are marked with scales to measure the insertion depth of the probe with an accuracy of $1 \mathrm{~mm}$. The connecting rod is a hollow steel tube of outer diameter $10 \mathrm{~mm}$, inner diameter $4 \mathrm{~mm}$, and length $700 \mathrm{~mm}$. It is connected to a pressure sensor through the thread; the pressure sensor and acceleration sensor are installed on the base. The cone head is fabricated 
according to American Society of Agriculture and Biological Engineers (ASABE) requirements; the conical diameter is $20 \mathrm{~mm}$ and conical angle is $30^{\circ}$. The doublemetal-ring SWR probe is mounted on the cone head to form the PSWR probe.

The double-metal-ring SWR probe is shown in Figure $1 b$. Two metal rings are mounted on a solid nylon column with grooves, and three PVC rings are installed between them for insulation, the probe spacing is $10 \mathrm{~cm}$. The metal rings are connected using wires as electrodes to the circuit, which measures the SWR. The wires and metal rings are welded together and installed in the grooves. The circuit, which measures the SWR, is located on the upper part of the probe to reduce the error caused by a change in the impedance around the wires, and is filled with waterproof glue to render it waterproof. The probe has an overall length of $150 \mathrm{~mm}$. The fabricated physical model is shown in Figure 1c.
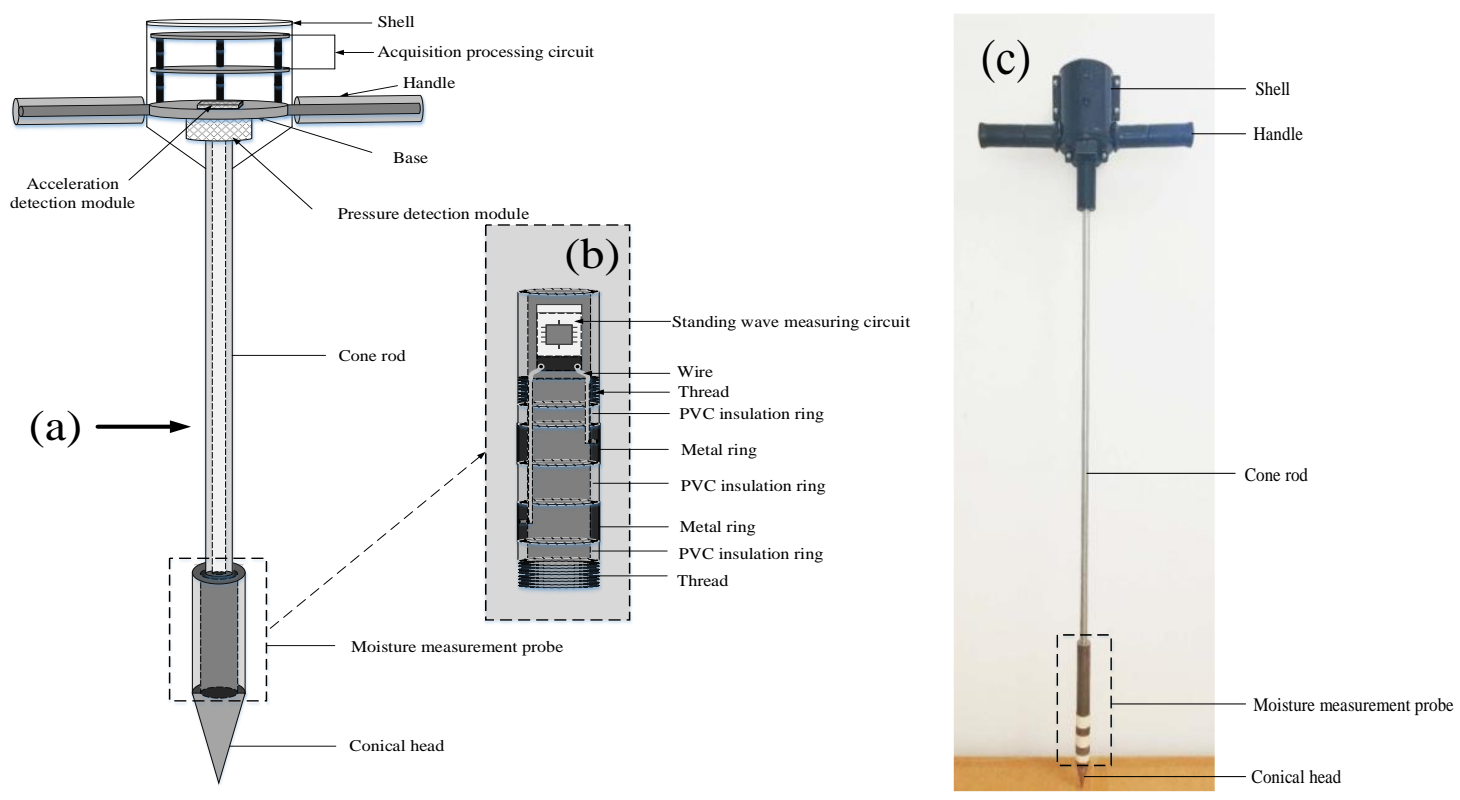

Figure 1. The assembly of a combined PSWR probe is illustrated: (a) Detailed schematic diagram showing the parts of the instrument; (b) Components of the double-metal-ring SWR probe are detailed; (c) Photograph of the actual physical model fabricated during the study is shown

\section{Soil compactness measurement based on cone index}

The ASABE (formerly the American Society of Agricultural Engineers) stipulates that when the standard cone is penetrated into the soil at a constant speed, the average pressure per unit area is the cone index $(C I)$, which can be used to characterize the soil compactness (ASAE S313.3 FEB04., 1998; ASABE Standards, 2009). The formula to calculate $C I$ is as follows Equation 1:

$$
C I=N / S=(F+G) / S
$$

where $N$ is the pressure at the bottom of the cone head, $S$ is the bottom area of the cone head, $F$ is the external force exerted by a person on the penetrometer, and $G$ is the force due to gravity on the instrument. 
However, during the actual measurement, it is difficult to maintain a uniform insertion speed; therefore, errors persist in the measurement results because of the complexity in the soil composition and non-standard manual operation. Hence, this study suggests a synchronous measurement of the external force $(F)$ and acceleration $(a)$ during the insertion of the cone. The pressure at the bottom of the cone can be calculated as follows Equation 2:

$$
N=F+G-m^{*} a
$$

where $m$ is the cone instrument quality. With this pressure, the corrected cone index can be calculated according to Equation 1, and the error caused by the variation in the velocity during the insertion can be eliminated.

\section{Measuring volumetric moisture content of soil based on SWR}

Moisture sensors based on SWR measure the dielectric constant of the soil. When high-frequency electromagnetic waves propagate along a transmission line, some of the incident waves are reflected by the probe placed in soil of different dielectric constant, because the impedance of the probe does not match with the impedance of the transmission line. Due to the interference of the reflected wave and the incident wave, a standing wave is formed on the transmission line, which causes a change in the voltage difference across the transmission line (Gaskin et al., 1996; Paltineanu et al., 1997). The moisture sensor designed in this study consists of a $100 \mathrm{MHz}$ crystal oscillator, coaxial transmission line, and double-metal-ring probe (Fig. 2). The voltage difference across the transmission line can be expressed as follows Equation 3:

$$
\Delta U=2 A \frac{Z_{P}-Z_{L}}{Z_{P}+Z_{L}}
$$

where $A$ is the electromagnetic wave amplitude $(V), Z_{P}$ is the probe impedance $(\Omega)$, and $Z_{L}$ is the transmission-line impedance $(\Omega) . Z_{L}$ is dependent on the physical dimensions and the dielectric constant of the insulating material (50 $\Omega$ in this research). $Z_{P}$ is determined by the probe size, soil permittivity, and operating frequency. The probe size and operating frequency are fixed values, which implies that a difference in the soil dielectric constant at the measurement site will change the impedance of the measuring probe, which results in a change in the voltage difference $(\Delta U)$ across the transmission line. The volumetric moisture content of soil has a relatively unique mathematical relationship with its dielectric constant (Topp, 2003; Yanuka et al., 1988); therefore, the moisture content can be measured by measuring the probe impedance.

\section{Filed sampling and instrument}

The soil samples were collected from Beijing Gongqing Forest Farm $\left(116.73^{\circ} \mathrm{E}\right.$, $\left.40.11^{\circ} \mathrm{N}\right)$ and Beijing Forestry University Sanqingyuan Experimental Base $\left(116.34^{\circ} \mathrm{E}\right.$, $40.00^{\circ} \mathrm{N}$ ), which are primarily used for teaching and research in the Beijing Forestry University. These sites experience a typical continental climate, with an average annual temperature of $11.6{ }^{\circ} \mathrm{C}$ and an average annual precipitation of $600 \mathrm{~mm}$. Areas of uniform soil were identified at the collection sites, and $30 \mathrm{~kg}$ of soil samples were extracted. These samples were dried $\left(48 \mathrm{~h}, 105^{\circ} \mathrm{C}\right)$ in an oven shown in Figure $3 d$. 
After drying, the samples were screened through a 40-mesh sieve shown in Figure $3 c$ to remove impurities, such as stones, dead branches, fallen leaves, and roots. Thus, the soil samples for the experiment were obtained, which were identified as sand soil (sand mass fraction $85 \%$, powder mass fraction $10 \%$, clay mass fraction $5 \%$ ) shown in Figure $3 a$ and clay loam soil (sand mass fraction $11 \%$, powder mass fraction $71 \%$, clay mass fraction 18\%) shown in Figure $3 b$.

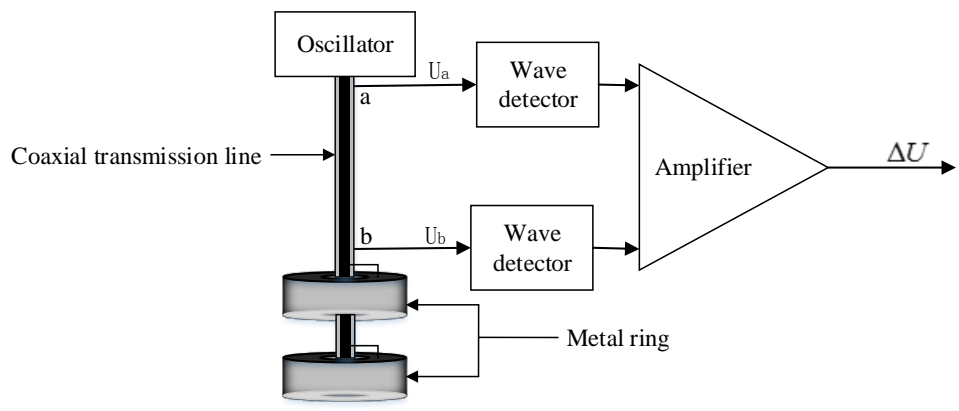

Figure 2. Diagram of the moisture sensor based on the standing wave ratio, and the measurement circuit. $U_{a}$ and $U_{b}$ are output voltages at Point $a$ and Point $b$ on the coaxial transmission line, respectively. $\Delta U$ is the differential output voltage between Point $a$ and Point $b$

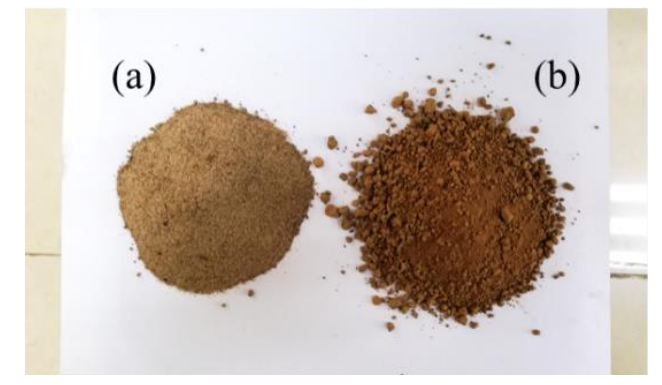

(c)

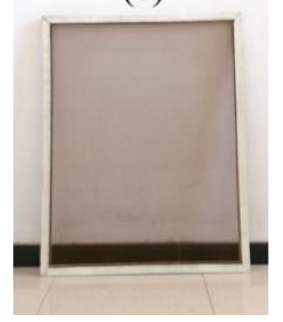

(d)

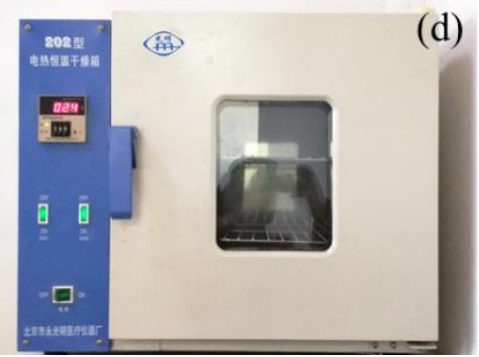

Figure 3. The details of soil sampling are presented: (a) Picture of the sampled sand soil; (b) Picture of the sampled clay loam soil; (c) 40-mesh sieve used for screening the impurities; (d) Drying oven used for drying the samples

The contrast instrument is SC-900 sensor (American Spectrum production, measuring unit $\mathrm{KPa}$, resolution is $35 \mathrm{KPa}$, measurement accuracy is $103 \mathrm{KPa}$, the range is $0-45 \mathrm{~cm}$ and $0-7000 \mathrm{KPa}$, maximum insertion speed is $25 \mathrm{~mm} \cdot \mathrm{s}-1$, maximum load is $95.25 \mathrm{~kg}$ ) and TDR sensor (German IMKO production, model TRIMEPICO32, measurement range $0-100 \%$ volume moisture content, measurement accuracy $\pm 2 \%$, probe diameter $3.5 \mathrm{~mm}$ and probe length $110 \mathrm{~mm}$ ).

The field experiments were conducted at Beijing Forestry University Forest Farm (altitude $\left.642 \mathrm{~m}, 116^{\circ} 4^{\prime} 36^{\prime \prime} \mathrm{E}, 40^{\circ} 3^{\prime} 42^{\prime} \mathrm{N}\right)$ and Beijing Forestry University Sanqingyuan Experimental Field (altitude 52 m, $116^{\circ} 20^{\prime} 15^{\prime \prime} \mathrm{E}, 40^{\circ} 0 ’ 44^{\prime \prime} \mathrm{N}$ ).

\section{Experimental procedure}

Two different soil samples of $10 \mathrm{~kg}$ each were weighed by a precision electronic weighing machine. A certain quantity of water was added to the samples and mixed thoroughly. The samples were detained for $48 \mathrm{~h}$ until the water movement attained 
equilibrium, and were subsequently placed in PVC buckets $(20 \mathrm{~cm}$ high, $30 \mathrm{~cm}$ diameter) and compacted uniformly using a nylon rod $(50 \mathrm{~cm}$ length, $5 \mathrm{~cm}$ diameter). Different trials were conducted by varying the water quantity and compaction of the soil samples; the combined probe was inserted into the soil samples to a penetration depth of $20 \mathrm{~cm}$, and the pressure and acceleration of the penetrations were recorded. The compactness of the samples was also measured using an SC-900 soil compactness meter, the SC-900 sensor is mounted on permanent magnet direct current motor (BXTL150, made in China, working voltage $12 \mathrm{~V}$, power $30 \mathrm{~W}$ ), the rotation of the motor drives the gear to rotate, which makes the SC-900 sensor move vertically downward uniformly $\left(12 \mathrm{~mm} \cdot \mathrm{s}^{-1}\right)$ along the guide rail to ensure that the SC-900 sensor measurement can obtain accurate soil compactness and be used as the true value of sample. The relation between the pressure and acceleration during the penetration were analyzed, and the effect of variation in the acceleration on the measurement results was investigated. The sensitive range of the double-metal-ring probe was analyzed by HFSS (High Frequency Structure Simulator) modeling and experimental analyses. Lumped port excitation method was assigned, and the value of frequency was set as $100 \mathrm{MHz}$ and fill dielectric constant as 21 (corresponding to a volumetric moisture content of $36 \%$ ). The metal ring was the ideal electric field boundary; a cylindrical body of diameter $20 \mathrm{~cm}$ and height $20 \mathrm{~cm}$ was assumed as the radiation boundary. Meanwhile, the soil column used for the experiment was thinned in steps of $1 \mathrm{~cm}$ thickness, the volumetric water content, compactness and height of soil columns remain unchanged, and the combined probe was inserted into the center of the sample; the output voltage of the probe corresponding to the diameter of the soil column was recorded for each step. After the calibration of the combined probe by the drying method, the accuracy and stability of the moisture measurement were analyzed by comparing the results with that from a TDR soil moisture sensor. Field experiments were finally carried out to verify the performance in practical conditions.

\section{Results and discussion}

\section{Relationship between penetration acceleration and pressure}

The acceleration $(a)$ and force $(F)$ data observed during the penetration were normalized, and the variations in pressure and acceleration are shown in Figure 4. Initially, the penetration force $(F)$ remains constant before the cone makes contact with the soil; it increases gradually as the cone touches the soil and continues the penetration, and then decreases rapidly to zero when penetration is stopped after reaching a certain depth $(20 \mathrm{~cm}$ in this case). Meanwhile, because it is difficult to main a uniform cone penetration manually, there is a fluctuation in the acceleration along the vertical direction. The initial penetration acceleration $(a)$ varies drastically when the cone reaches the soil, and the variation decreases as the cone continues to penetrate into the soil. The influence on the force at the bottom surface of the cone was calculated using Equation 2, and the measurement results after the acceleration correction were calculated. Table 1 is the measurement results of soil samples with different compactness and the depth of measurement is $10 \mathrm{~cm}$. It can be observed that the measurement error is reduced by measuring the penetration acceleration of the cone. 


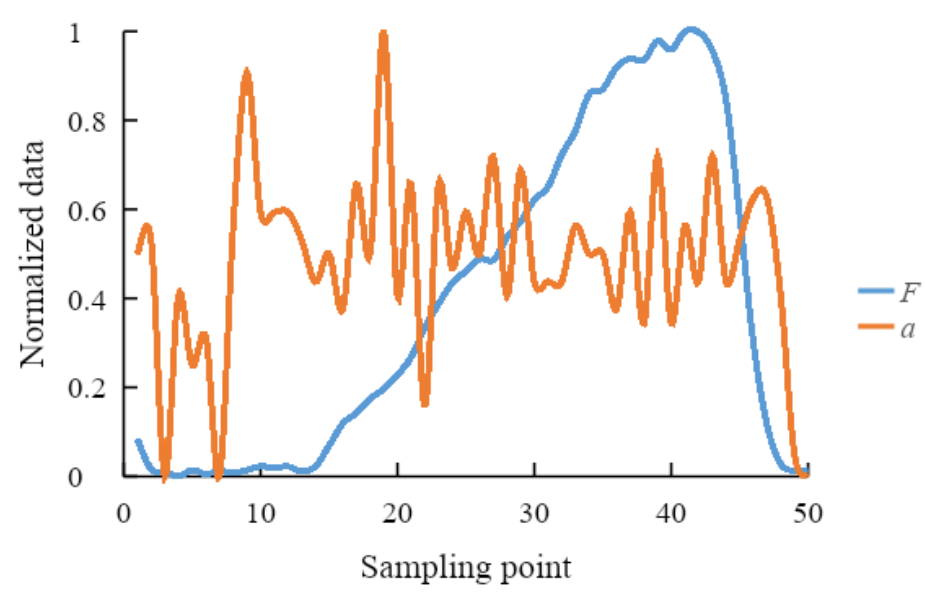

Figure 4. Variation in penetration pressure $(F)$ and acceleration $(a)$ during the cone penetration are plotted after normalization

Table 1. The results obtained from the two sensors are tabulated for comparison. For the composite sensor, the results before and after the acceleration correction are presented along with the corresponding error values

\begin{tabular}{|c|c|c|c|c|c|}
\hline \multirow{3}{*}{$\begin{array}{l}\text { Sample } \\
\text { number }\end{array}$} & \multirow{3}{*}{$\begin{array}{c}\mathrm{SC}-900 \\
\text { measurement } \\
\text { results (KPa) }\end{array}$} & \multicolumn{4}{|c|}{ Combined PSWR probe } \\
\hline & & \multicolumn{2}{|c|}{$\begin{array}{c}\text { Cone index (not counting } \\
\text { acceleration) }\end{array}$} & \multicolumn{2}{|c|}{$\begin{array}{c}\text { Cone index (calculation } \\
\text { acceleration) }\end{array}$} \\
\hline & & $\begin{array}{l}\text { Measurement } \\
\text { results (KPa) }\end{array}$ & $\begin{array}{c}\text { Relative } \\
\text { error } \\
\left(\mathrm{cm}^{3} \cdot \mathbf{c m}^{-3}\right)\end{array}$ & $\begin{array}{l}\text { Measurement } \\
\text { results (KPa) }\end{array}$ & $\begin{array}{c}\text { Relative } \\
\text { error } \\
\left(\mathrm{cm}^{3} \cdot \mathbf{c m}^{-3}\right)\end{array}$ \\
\hline 1 & 344 & 379.47 & $10.31 \%$ & 363.55 & $5.68 \%$ \\
\hline 2 & 380 & 392.90 & $3.40 \%$ & 379.33 & $0.18 \%$ \\
\hline 3 & 421 & 442.79 & $5.18 \%$ & 428.70 & $1.83 \%$ \\
\hline 4 & 526 & 541.28 & $2.90 \%$ & 532.68 & $1.27 \%$ \\
\hline 5 & 632 & 658.95 & $4.26 \%$ & 651.75 & $3.12 \%$ \\
\hline
\end{tabular}

\section{PSWR probe detection sensitive area}

The HFSS software was used to establish the simulation model of the probe. The electric field distribution of the annular probe is shown in Figure 5. It can be seen that the electric field strength gradually decreases as the diameter increases; at the boundary of $10 \mathrm{~cm}$ diameter, the electric field strength attenuates to $8 \mathrm{~V} / \mathrm{m}(1 \%$ of the center electric field strength). The variation of soil column diameter is shown in Figure 6. The variation of the voltage with the diameter of the soil column is shown in Figure 7; the output voltage begins to decrease rapidly when the diameter is $10 \mathrm{~cm}$, indicating that the sensitive range of the probe is within $10 \mathrm{~cm}$ diameter from the cone. Hence, to ensure accuracy in the measurement, it should be guaranteed that the soil within $10 \mathrm{~cm}$ diameter around the cone is uniform and does not contain debris and other impurities.

\section{Laboratory experiment for calibration}

For different values of volumetric moisture content of the soil samples, the corresponding voltage of the combined probe was measured and recorded; the relationship between the voltage and the volumetric moisture content is shown in 
Figure 8. For the clay loam and sand samples, the linear-fitting coefficient of output voltage and volumetric moisture content were 0.9694 and 0.9824 , respectively, and the fitting determination coefficients were higher than 0.96 . This indicates that the output voltage has a good linear relationship with the volumetric moisture content, and the volumetric moisture content can be calculated by fitting the curve.
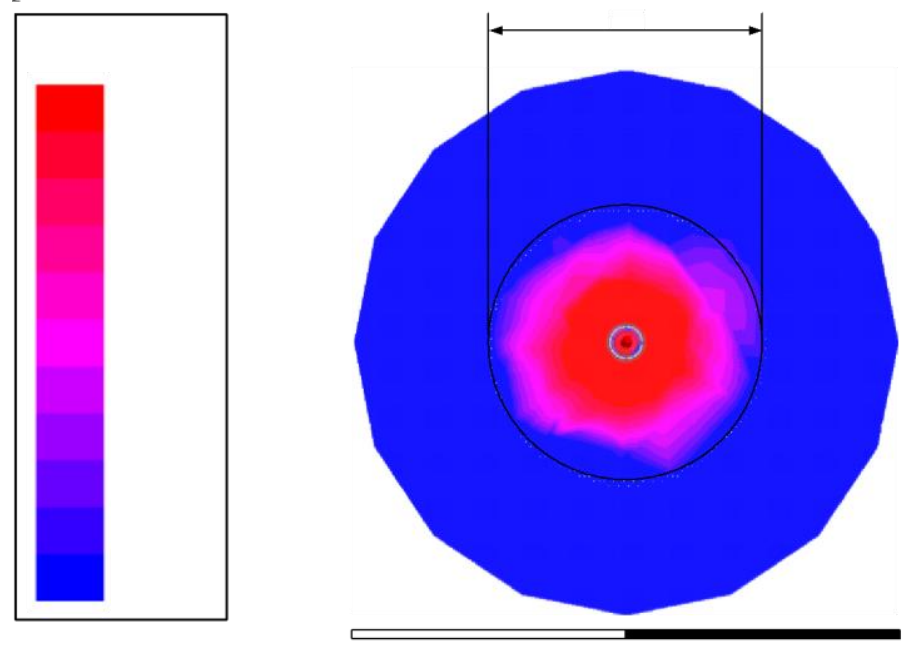

Figure 5. Electrical field distribution of double-metal-ring probe obtained by simulation is shown: top view of the model, which shows the distribution along the plan

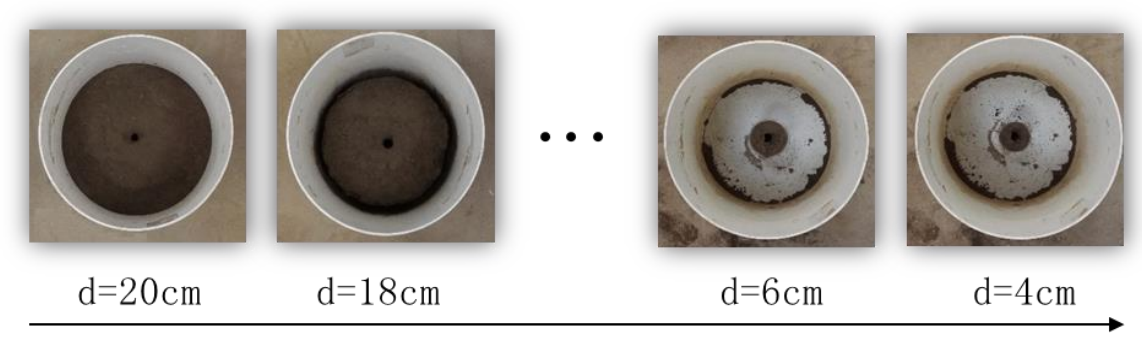

Figure 6. The gradual reduction of the soil column thickness of the sample during the metalring lateral-diameter test process is shown

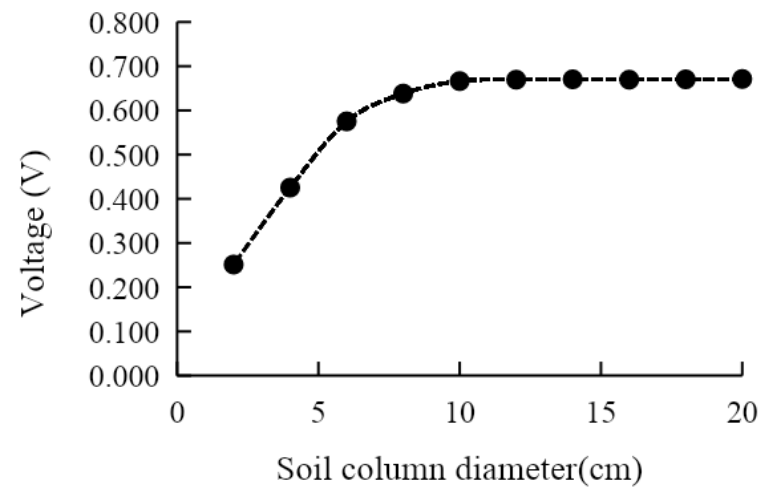

Figure 7. The variation in the output voltage with the diameter of the soil column is illustrated 


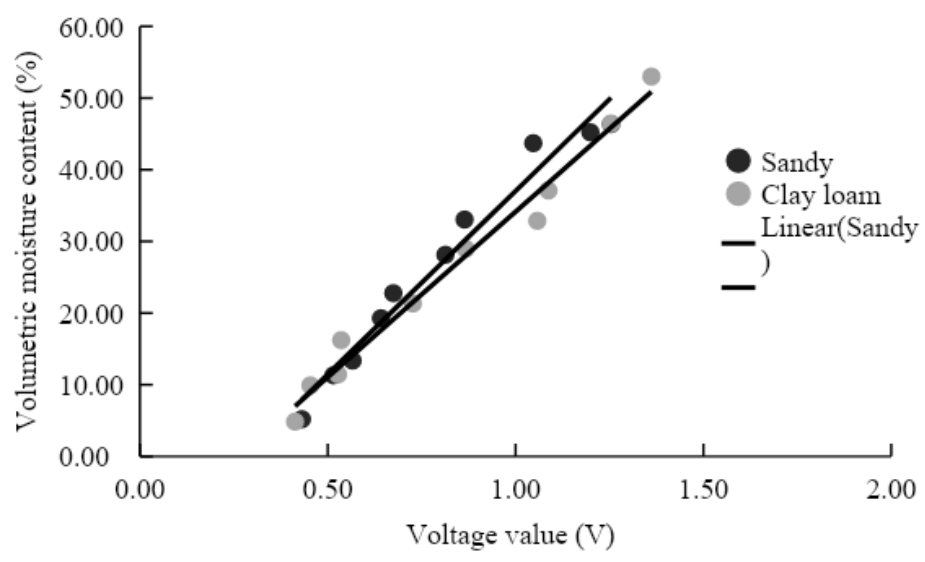

Figure 8. Relationship between the volumetric moisture content and the voltage value is depicted

\section{Laboratory measurement}

Figure 9 shows the variation in the volumetric moisture content of the soil measured by the probe in 100 repeated measurements in a sand sample of diameter $100 \mathrm{~cm}$ and height $20 \mathrm{~cm}$. It can be observed that the measurement results fluctuate very less; the maximum and minimum values of volumetric moisture content were $10.68 \%$ and $8.74 \%$, respectively, and the standard deviation was $0.49 \%$. Therefore, it is verified that the PSWR probe can be used for repeated measurements.

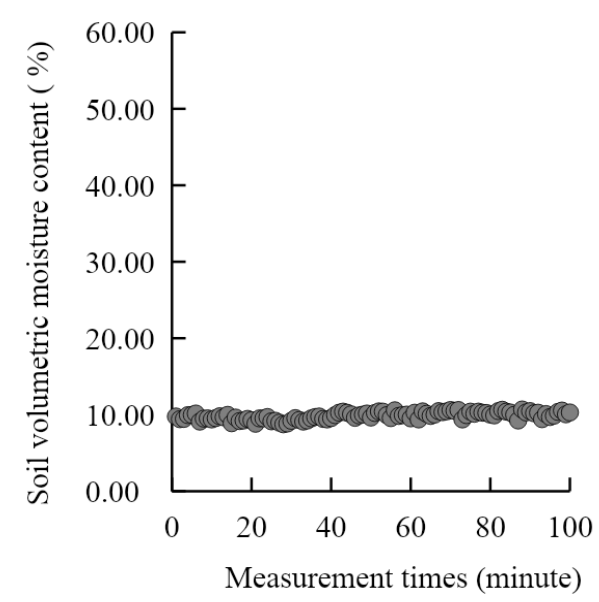

Figure 9. Results obtained from the repetitive measurements of moisture content are plotted

Figure 10 is a comparison of the results obtained from the proposed PSWR probe and TDR sensor in two soil types; twelve samples of different volumetric moisture content were prepared for each soil type. Measurement soil volumetric moisture content of the same sample with PSWR probe and TDR sensor respectively. It can be observed from Figure 10 that the results from the proposed probe are consistent with those from the TDR sensor. The results from the proposed PSWR probe and the TDR sensor were linearly fitted, as shown in Table 2 . The fitting determination coefficients prove that the measurement accuracies of the two devices are comparable, which satisfies the requirements of practical application. 


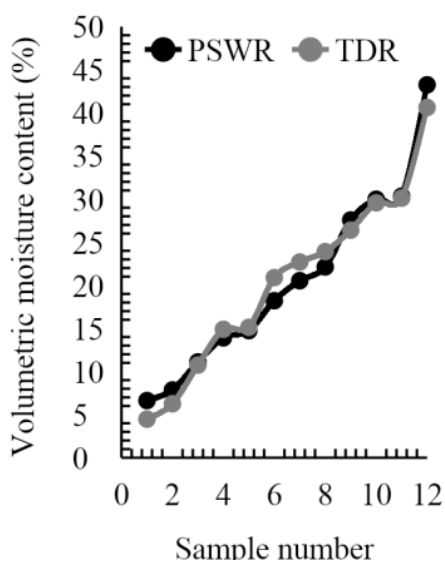

(a) Sandy

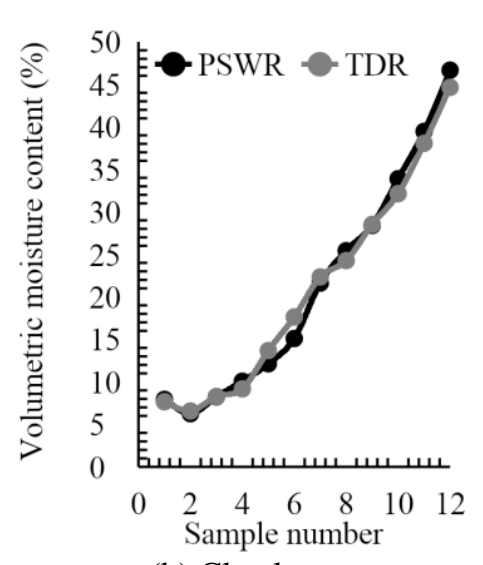

(b) Clay loam

Figure 10. The measurement results of the two devices are plotted together for comparison: Comparison of results obtained in (a) sandy soil, (b) clay loam soil

Table 2. The linear fitting expression and fitting determination coefficient $\left(R^{2}\right)$ of the results from the two devices are tabulated

\begin{tabular}{c|c|c}
\hline Soil type & Linear fit expression & $\mathbf{R}^{\mathbf{2}}$ \\
\hline Sandy & $\mathrm{y}=0.9745 \mathrm{x}+0.4743$ & 0.975 \\
Clay loam & $\mathrm{y}=0.9555 \mathrm{x}+1.2446$ & 0.9881 \\
\hline
\end{tabular}

Six samples of different volumetric moisture contents prepared using clay loam were subjected to three measurements per sample, simultaneously with the TDR sensor and the proposed PSWR probe, and the samples were dried to obtain the actual values of the volumetric moisture content. The data was recorded and the standard deviation of the measurements was calculated. As shown in Figure 11, the error fluctuation in the measurements of the six samples are approximately equivalent; the standard deviation of the results from the PSWR probe and TDR sensor were obtained as 2.32 and 1.63 , respectively. This indicates that the measurement stability of the PSWR probe is equivalent to that of the TDR sensor.

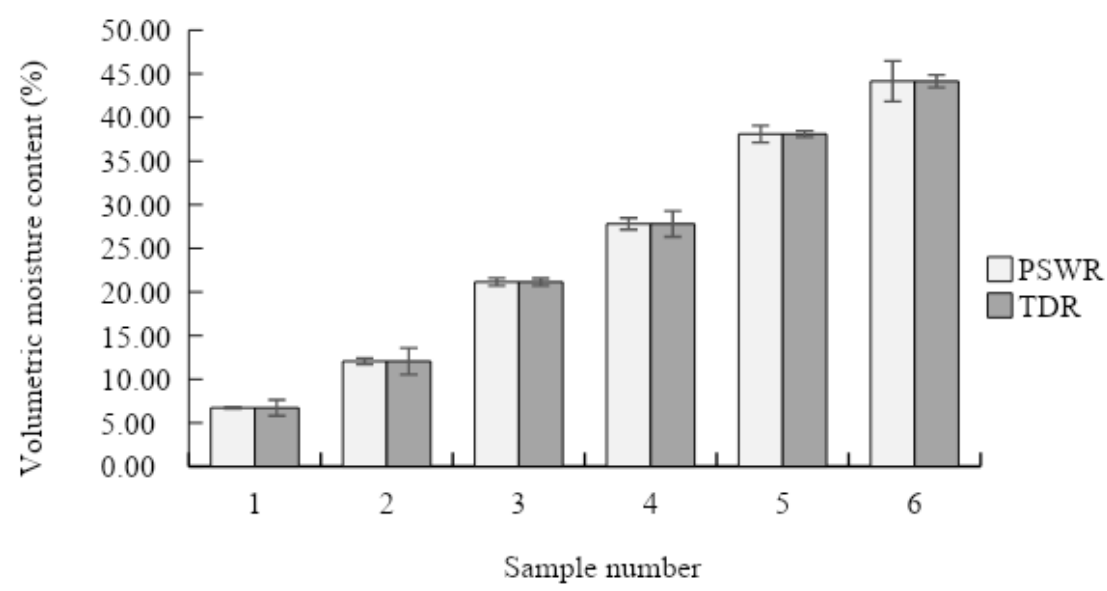

Figure 11. The moisture content obtained using the two devices are plotted to compare the measurement stability 


\section{Field measurement}

A square, flat land of area $9 \mathrm{~m}^{2}$ was selected at the sites, and the volumetric moisture content at five points were measured by the combined probe and by the drying method, as shown in Figure 12. The measurement depth was $20 \mathrm{~cm}$, and the comparison of measurement results is shown in Table 3. It can be observed that the measurement results are comparable; the maximum error was obtained as $2.10 \%$, which is less than $3 \%$; therefore, the proposed probe meets the accuracy requirements for practical use.

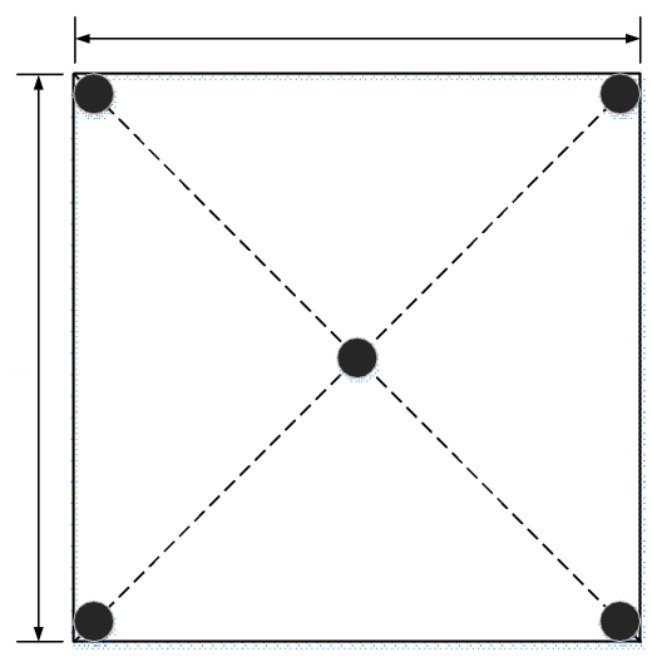

Figure 12. This diagram illustrates the points selected for the field measurements at the site

Table 3. The field measurement results obtained using the proposed probe and the drying method are tabulated for both the sites, $\theta_{V}$ is drying method and $\theta_{s}$ is PSWR method

\begin{tabular}{|c|c|c|c|c|}
\hline \multirow{2}{*}{ Measuring point } & \multicolumn{2}{|c|}{ Sanqingyuan experimental field } & \multicolumn{2}{|c|}{ Forest farm } \\
\hline & $\theta_{V}\left(\mathrm{~cm}^{3} \mathrm{~cm}^{-3}\right)$ & $\theta_{S}\left(\mathrm{~cm}^{3} \mathrm{~cm}^{-3}\right)$ & $\theta_{V}\left(\mathrm{~cm}^{3} \mathrm{~cm}^{-3}\right)$ & $\theta_{S}\left(\mathrm{~cm}^{3} \mathrm{~cm}^{-3}\right)$ \\
\hline 1 & $18.86 \%$ & $19.90 \%$ & $16.89 \%$ & $17.21 \%$ \\
\hline 2 & $21.44 \%$ & $21.85 \%$ & $15.67 \%$ & $17.35 \%$ \\
\hline 3 & $23.45 \%$ & $21.35 \%$ & $15.18 \%$ & $16.39 \%$ \\
\hline 4 & $21.11 \%$ & $19.61 \%$ & $14.80 \%$ & $16.57 \%$ \\
\hline 5 & $21.22 \%$ & $20.05 \%$ & $16.96 \%$ & $15.16 \%$ \\
\hline
\end{tabular}

Three sites were randomly selected in the field experimental site, The comparison of measurement results is shown in Figure 13, the soil compactness was measured by SC900 sensor and PSWR, the measured depth was $2.5 \mathrm{~cm}, 5.0 \mathrm{~cm}, 7.5 \mathrm{~cm}$ and $10.0 \mathrm{~cm}$. The results showed that the accuracy of PSWR measurement was the same as that of SC-900 sensor, and met the practical application requirements.

\section{Advantages of combined PSWR probe}

The existing compactness sensors based on cone index method are difficult to ensure uniform penetration due to manual operation, resulting in measurement errors due to different vertical velocities (Alaoui and Diserens, 2018; Pillinger et al., 2018; Lin et al., 2014). Moreover, the internationally recognized TDR sensor for moisture measurement has the disadvantage of high price and easy damage of probe (Rudnick et al., 2018; Sun 
et al., 2004; Yan et al., 2018). In view of the above shortcoming, the PSWR probe can simultaneously measure soil compactness and moisture content, the measurement error can be effectively reduced, and the accuracy of cone-index measurement can be improved by synchronously measuring the acceleration during the penetration. In addition, the PSWR probe has a lesser manufacturing cost and a more stable ring structure, and the soil compactness and volumetric moisture content can be measured synchronously by PSWR probe.

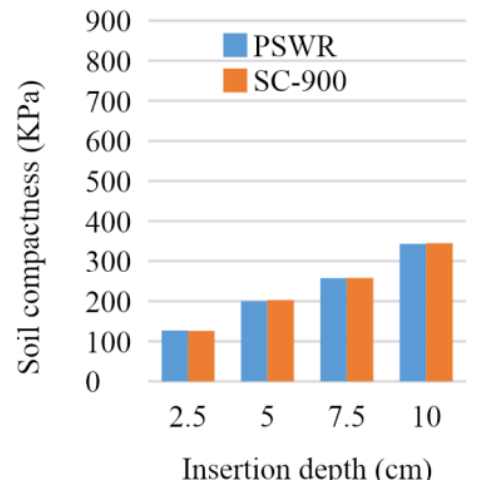

(a)

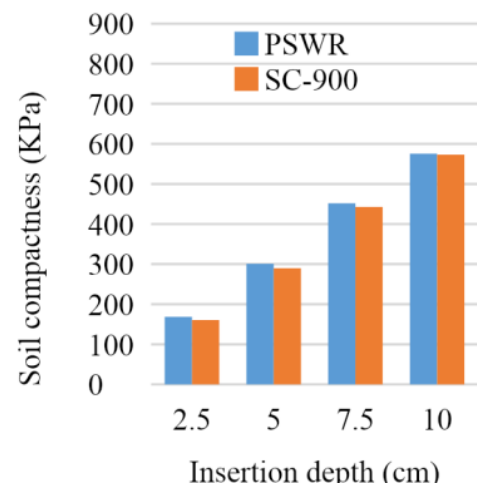

(b)

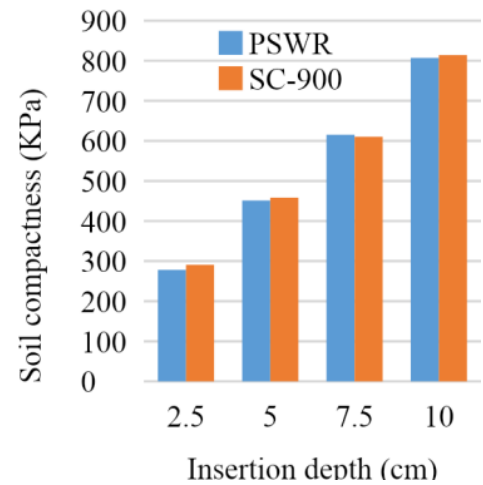

(c)

Figure 13. Comparison of field soil compactness measurement. (a) First, (b) second, (c) third measurement site

\section{Conclusions}

In this study, a combined penetrometer-SWR probe was designed and its performance was evaluated. Considering the errors caused by a varying penetration speed due to manual insertion during the cone-index measurement, we proposed to include synchronized acceleration measurement during the penetration process, and studied the acceleration and external force during the penetration process. The measurements errors were computed by comparing the results with that obtained from an SC-900 sensor, and the variation in the error after the acceleration compensation was observed. In addition, the measurement range of the double-metal-ring probe was analyzed and tested, and its performance was compared with that of a TDR sensor after calibration. Based on the experimental results, the following conclusions can be drawn:

First, there is a fluctuation in the penetration acceleration in the vertical direction, which causes a measurement error because of the complexity in the soil composition and non-standard manual operation during the penetration. The PSWR probe reduces the measurement error and improves the measurement accuracy by simultaneously measuring penetration acceleration.

Second, the HFSS simulation analysis and experiments show that the sensitive range of the PSWR probe designed in this study is within $10 \mathrm{~cm}$ diameter around the cone. To ensure accuracy in the results, the point of measurement should be selected such that the soil within a diameter of $10 \mathrm{~cm}$ is uniform and does not contain other impurities, such as gravel.

Third, calibration of the PSWR probe in the laboratory indicates that the output voltage has a significant linear relationship with the volumetric moisture content of the soil. The indoor tests prove that the moisture measurement probe can maintain a stable 
output across multiple measurements; the results are comparable to that of a TDR sensor in terms of accuracy and stability.

Finally, the field measurement results obtained using the combined probe was compared to the drying-measurement results, and the maximum error in the volumetric moisture content measurement was obtained as $2.10 \%$, which is less than $3 \%$. This implies that the measurements by the combined probe are consistent with the results from the drying method, which satisfies the requirements for the practical implementation of the proposed probe.

Soil volumetric water content is closely related to soil compactness, soil porosity and soil bulk density, exploring the coupling relationship between them and establishing the coupling model will be the focus of future research.

Acknowledgements. This work is supported by the Fundamental Research Funds for the Central Universities (Grant No.2019YC15), the National Key Research and Development Program of China (Grant No.2017YFD0600901) and Special Fund for Beijing Common Construction Project.

\section{REFERENCES}

[1] Alaoui, A., Diserens, E. (2018): Mapping soil compaction. A review. - Current Opinion in Environmental Science \& Health 5: 60-66.

[2] ASABE Standards (2009): EP542: Procedures for Using and Reporting Data Obtained With the Soil Cone Penetrometer. - ASABE, St. Joseph, MI.

[3] ASAE S313.3 FEB04. (1998): Soil Cone Penetrometer. - ASAE, S. America.

[4] Cui, F., Wu, Z. Y., Wang, L., et al. (2015): Application of the ground penetrating radar ARMA power spectrum estimation method to detect moisture content and compactness values in sandy loam. - Journal of Applied Geophysics 120: 26-35.

[5] Erbach, D. C., Kinney, G. R., Wilcox, A. P., et al. (1991): Strain gage to measure soil compaction. - Transactions of the ASAE 34(6): 2345-2348.

[6] Gaskin, G. J., Miller, J. D. (1996): Measurement of soil water content using a simplified impedance measuring technique. - Agric. Eng. Res. 63: 153-159.

[7] Goutal, N., Keller, T., Défossez, P., et al. (2013): Soil compaction due to heavy forest traffic: measurements and simulations using an analytical soil compaction model. Annals of Forest Science 70(5): 545-556.

[8] Hummel, J. W., Ahmad, I. S., Sudduth, K. A., et al. (2004): Simultaneous soil moisture and cone index measurement. - Transactions of the ASAE 47(3): 607-618.

[9] Jin-Hong, X. U., Rui-Song, X. U., Miao, L. (2008): Quantitative analysis of moisture content and fieldspectrum of red soil. - Science of Surveying \& Mapping 33(5): 43-45.

[10] Lin, J., Sun, Y., Lammers, P. S. (2014): Evaluating model-based relationship of cone index, soil water content and bulk density using dual-sensor penetrometer data. - Soil \& Tillage Research 138: 9-16.

[11] Luo, X., Perumpral, J. V. (1995): Study on soil strength with microwave reflection loss. Transactions of the Chinese Society of Agricultural Engineering 11(1): 46-51.

[12] Mossadeghi-Björklund, M., Arvidsson, J., Keller, T., et al. (2016): Effects of subsoil compaction on hydraulic properties and preferential flow in a Swedish clay soil. - Soil \& Tillage Research 156: 91-98.

[13] Ogée, J., Brunet, Y. (2002): A forest floor model for heat and moisture including a litter layer. - Hydrol. 255: 212-233.

[14] Paltineanu, I. C., Starr, J. L. (1997): Real-time soil water dynamics using multisensor capacitance probes: laboratory calibration. - Soil Sci. Soc. Am. J. 61: 1576-1585. 
[15] Perumpral J. V. (1987): Cone penetrometer applications - a review. - Trans. ASAE 30(4): 0939-0944.

[16] Pillinger, P., Géczy, A., Hudoba, Z., et al. (2018): Determination of soil density by cone index data. - Journal of Terramechanics 77: 69-74.

[17] Ronai, D., Shmulevich, I. (1995): Comparative analysis of some soil compaction measurement techniques. - International Agrophysics 9(3): 165-182.

[18] Rudnick, D. R., Lo, T., Singh, J., et al. (2018): Reply to comments on "Performance assessment of factory and field calibrations for electromagnetic sensors in a loam soil." Agricultural Water Management 203: 272-276.

[19] Schaap, M. G., Bouten, W., Verstraten, J. M. (1997): Forest floor water content dynamics in a Douglas fir stand. - Hydrol. 201: 367-383.

[20] Singh, G., Das, B. M., Chong, M. K. (1997): Measurement of moisture content with a penetrometer. - Geotechnical Testing Journal 20(3): 317-323.

[21] Sun, Y., Schulze Lammers, P., Ma, D. (2004): Evaluation of a combined Penetrometer for simultaneous measurement of penetration resistance and soil water content. - Journal of Plant Nutrition and Soil Science 167: 745-751.

[22] Topp, G. C. (2003): Laboratory calibration, in-field validation and use of a soil penetrometer measuring cone resistance and water content. - Vadose Zone Journal 2(4): 633-641.

[23] Topp, G. C., Davis, J. L., Annan, A. P. (1980): Electromagnetic determination of soil water content: Measurements in coaxial transmission lines. - Water Resources Research 16(3): 574-582.

[24] Tranter, G., Minasny, B., Mcbratney, A. B., et al. (2008): Comparing spectral soil inference systems and mid-infrared spectroscopic predictions of soil moisture retention. Soil Science Society of America Journal 72(5): 1394-1400.

[25] Vaz, C. M. P., Hopmans, J. W. (2001): Simultaneous measurement of soil penetration resistance and water content with a combined penetrometer-TDR moisture probe. - Soil Sci. Soc. Am. 65(1): 4-12.

[26] Vaz, C. M. P., Bassoi, L. H., Hopmans, J. W. (2001): Contribution of water content and bulk density to field soil penetration resistance as measured by a combined cone penetrometer-TDR probe. - J. Soil \& Tillage Research 60(1): 35-42.

[27] Yan, X., Zhao, Y., Cheng, Q., et al. (2018): Determining forest duff water content using a low-cost standing wave ratio sensor. - Sensors 18(647): 1-11.

[28] Yanuka, M., Topp, G. C., Zegelin, S., et al. (1988): Multiple reflection and attenuation of time domain reflectometry pulses: theoretical considerations for applications to soil and water. - J. Water Resources Research 24(7): 939-944.

[29] Zegelin, S. J., White, I., Jenkins, D. R. (1989): Improved field probes for soil water content and electrical conductivity measurement using time domain reflectometry. Water Resources Research 25(11): 2367-2376.

[30] Zoughi, R., Gray, S., Nowak, P. S. (1994): Cement paste compressive strength estimation using nondestructive microwave reflectometry. - Proceedings of SPIE - The International Society for Optical Engineering 2275: 89-93. 